Journal of Patient-Centered

\title{
First-Case Operating Room Delays: Patterns Across Urban Hospitals of a Single Health Care System
}

Callie M. Cox Bauer

Danielle M. Greer

Kiley B. Vander Wyst

Scott A. Kamelle

Follow this and additional works at: https://aah.org/jpcrr

Part of the Operations and Supply Chain Management Commons, and the Surgery Commons

\section{Recommended Citation}

Cox Bauer CM, Greer DM, Vander Wyst KB, Kamelle SA. First-case operating room delays: patterns across urban hospitals within a single health care system. J Patient Cent Res Rev. 2016;3:125-35. doi: 10.17294/ 2330-0698.1265

Published quarterly by Midwest-based health system Advocate Aurora Health and indexed in PubMed Central, the Journal of Patient-Centered Research and Reviews (JPCRR) is an open access, peer-reviewed medical journal focused on disseminating scholarly works devoted to improving patient-centered care practices, health outcomes, and the patient experience. 


\title{
First-Case Operating Room Delays: Patterns Across Urban Hospitals Within a Single Health Care System
}

\author{
Callie M. Cox Bauer, DO, ${ }^{1}$ Danielle M. Greer, PhD, ${ }^{2}$ Kiley B. Vander Wyst, MPH, ${ }^{2}$ Scott A. Kamelle, $\mathrm{MD}^{3}$ \\ ${ }^{1}$ Department of Obstetrics and Gynecology, Aurora Sinai Medical Center, Aurora Health Care, Milwaukee, WI \\ ${ }^{2}$ Aurora University of Wisconsin Medical Group and Center for Urban Population Health, Aurora Health Care, \\ Milwaukee, WI \\ ${ }^{3}$ Department of Oncology, Aurora St. Luke’s Medical Center, Aurora Health Care, Milwaukee, WI
}

\begin{abstract}
Purpose Operating room delays decrease health care system efficiency and increase costs. To improve operating room efficiency in our system, we retrospectively investigated delay frequencies, causes and costs.

Methods We studied all first-of-the-day nonemergent surgical cases performed at three high-volume urban hospitals of a large health system from July 2012 to November 2013. Times for patient flow from arrival to procedure start and documented reasons for delay were obtained from electronic medical records. Delay was defined as patient placement in the operating room later than scheduled surgery time. Effects of patient characteristics, late patient arrival to the hospital, number of planned procedures, years of surgeon experience, service department and hospital facility on odds of delay were examined using logistic regression.
\end{abstract}

Results Of 5,598 cases examined, $88 \%$ were delayed. Patients arrived late to the hospital ( $<2$ hours before scheduled surgery) in $65 \%$ of first cases. Mean time from arrival to scheduled surgery and in-room placement was 104.6 and 127.4 minutes, respectively. Mean delay time was 28.2 minutes. Nearly $60 \%$ of delayed cases had no documented reason for delay. For cases with documentation, causes included the physician (52\%), anesthesia (15\%), patient (13\%), staff $(9 \%)$, other sources $(6 \%)$ and facility $(5 \%)$. Regression analysis revealed age, late arrival, department and facility as significant predictors of delay. Estimated delay costs, based on published figures and representing lost revenue, were $\$ 519,388$.

Conclusions To improve operating room efficiency, multidisciplinary strategies are needed for increasing patient adherence to recommended arrival times, documentation of delay by medical staff and consistency in workflow patterns among facilities and departments. (J Patient Cent Res Rev. 2016;3:125-135.)

Keywords operating room; workflow; efficiency; first case of the day; surgery; start time; case delay

In a health care environment driven by cost containment, patient satisfaction and physician-centered reimbursement, hospital systems now pay increasing attention to waste reduction and workflow efficiency. Efficiency within the operating room (OR) has become a priority for many institutions, demonstrating significant potential for improvement in budgetary adherence. ${ }^{1,2}$ However, numerous elements contribute to success in OR workflow, making it difficult to pinpoint when and

Correspondence: Callie M. Cox Bauer, DO,

Department of Obstetrics and Gynecology,

Brook Army Medical Center, 3551 Roger Brooke Drive,

Fort Sam Houston, TX, 78234, T: 210-916-1162,

Email: Callie.M.Coxbauer.mil@mail.mil where most failures occur. Without such information, the development of action plans for improving efficiency are challenging, if not impossible.

Success of an OR day depends largely on outcomes of the day's first surgical cases. Maximal utilization of the OR requires on-time starts and efficient room turnover. ${ }^{3}$ These criteria for success depend on key roles played by multiple components of the OR system, including specialized staff and equipment as well as patient- and system-driven factors. Multiple strategies have been devised for establishing OR management systems that coordinate all members of the OR team. ${ }^{4-7}$ Such strategies include identification of key performance indicators, which have led to the establishment of 
national benchmarks that allow for comparisons among U.S. hospitals and provide individual institutions with targets for success. National benchmarks have been reported for first-case on-time starts, room turnover time, accurate case-duration estimation, patient into-incision time, patient close-to-out time and primetime (0700-1500) utilization. ${ }^{8}$ Despite definition of these benchmarks, however, a paucity of data exists on first-case start times and causes for delay within multihospital systems.

The goal of this study was to examine patterns in OR workflow at three high-volume urban hospitals in the same health care system. Specific objectives were to: 1) determine if on-time start for first surgical cases differed by hospital facility, and 2) determine if patterns existed in reasons for start delay by hospital facility and service department. Ultimately, we sought to assess compliance with national benchmarks, to make inferences regarding the financial or inefficiency costs of delay and to provide recommendations for future improvement.

\section{METHODS}

We retrospectively studied all patients aged $\geq 18$ years who underwent first-case-of-the-day surgeries at three hospitals in a large health system from July 2012 through November 2013. Hospital 1 has a total of 680 inpatient beds and services 39,104 outpatient and 28,395 inpatient surgeries per year. Hospital 2 has 117 total inpatient beds and services 9,154 outpatient and 7,529 inpatient surgeries per year. Lastly, Hospital 3 has 220 inpatient beds and services 15,839 outpatient and 11,619 inpatient surgeries each year. Patient, surgical and physician data were gathered from the electronic medical record, and cases were identified as delayed when patients were placed in the OR after scheduled surgery times. The study protocol was reviewed by the local institutional review board and deemed nonhuman subjects research.

To describe overall and hospital-specific patient and surgical characteristics within our study population, we computed frequencies and means with $95 \%$ confidence intervals (CI), as appropriate per variable type. Differences in proportions and means across hospitals were tested using Pearson's chi-squared test of independence and analysis of variance
(ANOVA), respectively. Assumptions of sample size, independence and normality were satisfied for all tests.

On-time start was defined (by national standard) to be inroom time equal to or before scheduled surgical time. To examine the flow of patients from arrival to procedure time, we computed mean deviations from scheduled surgery time to each of four events: patient arrival at the hospital, placement of patient in the OR, start of anesthesia, and start of procedure. We also computed the mean lengths of intervals between events, including from arrival to room, from room to anesthesia and from anesthesia to procedure. Deviations and interval lengths were computed overall, per hospital facility and by surgical service (general; ear/nose/throat [ENT], head/ neck, and oral; gynecologic, gynecologic-oncologic, and urologic-gynecologic; urologic; orthopedic; neurologic; all others combined). To further examine patterns in surgical case delay, we computed the frequency of delayed cases and mean delay time per hospital facility in relation to service department combination. We also described the frequency and distribution of delayed cases across specified reasons for delay, including fault of the patient, facility, surgeon, anesthesia, staff and other source. This was examined for overall system, per facility and per department.

We used mixed-effects logistic regression to determine the most important variables influencing the binary response of surgical case delay (yes or no). Model effects, whether fixed or random, represented a priori hypotheses concerning sources of variation in delay. Fixed effects included patient age, sex, race/ethnicity, body mass index, presurgery overnight hospital stay (yes or no), late patient arrival ( $<2$ hours early) to the hospital (yes or no), number of planned procedures during surgery, maximum years of surgical experience among participating surgeons, surgical service provided and hospital facility. Number of planned procedures, calculated by the number of individual planned procedures as documented in the record, was used secondary to the needs for increased set-up time with increasing number of procedures. Due to limited numbers, patients of non-Hispanic Asian, Native Islander, Native American and unknown race/ethnicity as well as those categorized as surgical service "other" were excluded from regression analysis. All fixed-effect variables were examined in both single-variable and multivariable models, and in all models, month (1-12) 
nested within hospital facility was included as a random effect, subsequently defining 36 separate adjustments to the model intercept.

As late patient arrival depended on presurgery overnight stay, two multivariable models were developed, each containing one of the two associated variables (late arrival or overnight stay) plus all other explanatory variables. Within each multivariable model, we initially included four two-variable interactions (age $\times$ sex, age $\times$ race/ethnicity, sex $\times$ race/ethnicity, and hospital facility $\times$ surgical service). Nonsignificant interaction terms were sequentially removed, starting with the interaction of largest P-value, until only statistically significant interactions remained. We present results for the better fitting multivariable model, identified as the model with lowest Akaike information criterion value. For all models, odds ratios represented measures of effect size, derived to demonstrate difference in odds of delay between categories or levels of each explanatory variable. All analyses were performed using SAS statistical software (Version 9.4; SAS Institute Inc., Cary, NC). In all cases, $\mathrm{P}<0.05$ was considered statistically significant.

\section{RESULTS}

Characterization of the study population was important for understanding the relative influence of individual hospitals on overall outcomes. Of 5,598 total first-of-theday surgeries, over $45 \%$ were performed at Hospital 3, $33 \%$ at Hospital 1 and $21 \%$ at Hospital 2 (Table 1) Overall, patient placement in the OR was delayed for $88 \%$ of cases (Table 2 ). For delayed cases only, average delay time was 28 minutes. The percentage of cases resulting in delay was significantly greater at Hospital 1 (98\%) than Hospital 2 (81\%) and Hospital 3 (85\%), with respective mean delay in minutes of 50, 11 and 11. Variability in this percentage was evident among departments overall (75-98\%) and at both Hospital 2 (68-86\%) and Hospital 3 (64-92\%). The percentage delayed at Hospital 1, in contrast, was consistent among departments, revealing $97-100 \%$ of cases as delayed. In evaluation of services across all institutions and total patients with a delay, neurosurgery had the most and ENT, head/neck and oral surgery had the least (Table 2).

All surgical case characteristics examined, except within-year timing, demonstrated differences among hospitals. Patients at Hospital 1 were older (mean 57 years), nearly equal in gender representation (55\% female) and predominantly white (80\%). Hospital 2 cared for the youngest group (mean 47 years), which was principally female $(70 \%)$ and nonwhite $(52 \%)$. Patients at Hospital 3 were of intermediate age (mean 51 years) and predominantly female $(74 \%)$ and white $(83 \%)$.

While hospital facilities showed similar case distributions across seasons, differences in overnight stay and within-day timing of surgeries were evident (Table 1). Hospital 1 had the highest percentage of overnight stays but lowest percentage of early morning (0700-0800) surgeries; patterns were opposite at Hospital 3, and Hospital 2 revealed intermediate levels. Patients at Hospital 3 were more likely to arrive at the hospital late (i.e. within 2 hours of scheduled surgery time). Mean number of planned surgical procedures was greatest at Hospital 3 and least at Hospital 1. Mean provider experience was $\geq 20$ years at all hospitals but greatest at Hospital 2 and least at Hospital 1. Per hospital facility, the top service department by surgical case frequency was general surgery at Hospital 1, orthopedics at Hospital 2 and gynecology/gynecologic oncology/urologic gynecology at Hospital 3.

Across all hospital facilities and departments, 65\% of all cases (and $75 \%$ of cases with same-day arrival) began with late patient arrival at the hospital; fewer than $1 \%$ of all patients arrived after scheduled surgery time (Table 1). Hospital 1 had the highest number of patients, with late arrivals accounting for $81 \%$, followed by Hospital 3 (72\%), and Hospital 2 (72\%). Mean event times revealed that patients arrived 1.75 hours prior to scheduled surgery time (if not during the night before) and were placed in the OR and received anesthesia 24 minutes later than scheduled surgery time (Table 3). Procedure start time, on average, occurred 1 hour after scheduled surgery time. Event times were consistently and significantly later at Hospital 1 than Hospital 2 and Hospital 3. At Hospital 1, patients arrived later but also waited longer, 2.5 hours for in-room placement and 3 hours for procedure start. Deviations from scheduled surgery time and interval lengths were similar between Hospital 2 and Hospital 3. Among service departments, neurosurgery demonstrated the most dramatic delays in arrival, OR placement and procedure start times and, consequently, longer wait times for patients. Arriving 
Table 1. Characteristics of First-of-the-Day Surgical Cases at Three Urban Hospitals (July 2012-November 2013)

\begin{tabular}{|c|c|c|c|c|}
\hline Surgical case characteristics & $\begin{array}{c}\text { All hospitals } \\
(n=5,598)\end{array}$ & $\begin{array}{l}\text { Hospital } 1 \\
(n=1,848)\end{array}$ & $\begin{array}{c}\text { Hospital } 2 \\
(n=1,218)\end{array}$ & $\begin{array}{c}\text { Hospital } 3 \\
(n=2,532)\end{array}$ \\
\hline Patient age in years, mean $(95 \% \mathrm{Cl})^{\mathrm{a}}$ & $52.4(51.9-52.8)$ & $57.3(56.6-58.0)$ & $46.9(46.0-47.8)$ & $51.4(50.7-52.1)$ \\
\hline Female sex, $\mathrm{n}(\%)^{\mathrm{a}}$ & $3,750(67.0)$ & $1,011(54.7)$ & $856(70.3)$ & $1,883(74.4)$ \\
\hline $\begin{array}{l}\text { Race/ethnicity, n (\%)a } \\
\text { White non-Hispanic } \\
\text { Black non-Hispanic } \\
\text { Asian non-Hispanic } \\
\text { Native American non-Hispanic } \\
\text { Native Islander non-Hispanic } \\
\text { Hispanic/Latino }\end{array}$ & $\begin{array}{l}4,157(74.3) \\
916(16.4) \\
59(1.05) \\
17(0.30) \\
2(0.04) \\
389(6.95)\end{array}$ & $\begin{array}{c}1,476(79.9) \\
182(9.85) \\
16(0.87) \\
10(0.54) \\
1(0.05) \\
152(8.23)\end{array}$ & $\begin{array}{l}582(47.8) \\
505(41.5) \\
19(1.56) \\
2(0.16) \\
1(0.08) \\
90(7.39)\end{array}$ & $\begin{array}{l}2,099(82.9) \\
229(9.04) \\
24(0.95) \\
5(0.20) \\
0(0.00) \\
147(5.80)\end{array}$ \\
\hline Body mass index in $\mathrm{kg} / \mathrm{m}^{2}$, mean $(95 \% \mathrm{Cl})^{a}$ & $30.7(30.5-30.9)$ & $30.4(30.0-30.7)$ & $32.0(31.5-32.5)$ & $30.3(30.0-30.6)$ \\
\hline $\begin{array}{l}\text { Season within the year, n (\%) } \\
\text { Spring (Mar-May) } \\
\text { Summer (Jun-Aug) } \\
\text { Autumn (Sep-Nov) } \\
\text { Winter (Dec-Feb) }\end{array}$ & $\begin{array}{l}1,417(25.3) \\
1,398(25.0) \\
1,409(25.2) \\
1,374(24.5)\end{array}$ & $\begin{array}{l}481(26.0) \\
460(24.9) \\
470(25.4) \\
437(23.6)\end{array}$ & $\begin{array}{l}302(24.8) \\
307(25.2) \\
303(24.9) \\
306(25.1)\end{array}$ & $\begin{array}{l}634(25.0) \\
631(24.9) \\
636(25.1) \\
631(24.9)\end{array}$ \\
\hline Patient arrival during previous night, $\mathrm{n}(\%)^{\mathrm{a}}$ & $727(13.0)$ & $415(22.4)$ & $147(12.1)$ & $165(6.52)$ \\
\hline $\begin{array}{l}\text { Patient arrival after scheduled procedure } \\
\text { time, } n(\%)\end{array}$ & $24(0.43)$ & $19(1.03)$ & $4(0.33)$ & $1(0.04)$ \\
\hline $\begin{array}{l}\text { Patient arrival }<2 \text { hours before scheduled } \\
\text { procedure time, } \mathrm{n}(\%)^{\mathrm{a}}\end{array}$ & $3,646(65.1)$ & $1,166(63.1)$ & $771(63.3)$ & $1,709(67.5)$ \\
\hline $\begin{array}{l}\text { Hour of scheduled procedure, } \mathrm{n}(\%)^{\mathrm{a}} \\
0700-0759 \\
0800-0859 \\
0900-0959\end{array}$ & $\begin{array}{l}3,281(58.6) \\
1,017(18.2) \\
1,300(23.2)\end{array}$ & $\begin{array}{l}850(46.0) \\
572(31.0) \\
426(23.1)\end{array}$ & $\begin{array}{l}705(57.9) \\
206(16.9) \\
307(25.2)\end{array}$ & $\begin{array}{l}1,726(68.2) \\
239(9.44) \\
567(22.4)\end{array}$ \\
\hline No. of planned procedures, mean $(95 \% \mathrm{Cl})^{\mathrm{a}, \mathrm{b}}$ & $1.39(1.37-1.42)$ & $1.08(1.07-1.10)$ & $1.30(1.26-1.34)$ & $1.67(1.63-1.71)$ \\
\hline Years of surgeon experience, mean $(95 \% \mathrm{Cl})^{\mathrm{a}}$ & $21.5(21.2-21.8)$ & $19.6(19.1-20.1)$ & $24.6(24.0-25.2)$ & $21.3(20.9-21.6)$ \\
\hline $\begin{array}{l}\text { Service department, n (\%) } \\
\text { General surgery } \\
\text { ENT, HN, Oral } \\
\text { Gyn, GynOnc, UroGyn } \\
\text { Urology } \\
\text { Orthopedics } \\
\text { Neurosurgery } \\
\text { Other }\end{array}$ & $\begin{array}{l}1,490(26.6) \\
295(5.27) \\
1,301(23.2) \\
282(5.04) \\
1,490(26.6) \\
399(7.13) \\
341(6.09)\end{array}$ & $\begin{array}{l}732(39.6) \\
94(5.09) \\
54(2.92) \\
94(5.09) \\
448(24.2) \\
348(18.8) \\
76(4.11)\end{array}$ & $\begin{array}{l}299(24.5) \\
1(0.08) \\
275(22.6) \\
56(4.60) \\
511(42.0) \\
0(0.00) \\
76(6.24)\end{array}$ & $\begin{array}{l}459(18.1) \\
200(7.90) \\
972(38.4) \\
130(5.13) \\
531(21.0) \\
51(2.01) \\
189(7.46)\end{array}$ \\
\hline
\end{tabular}

a Statistically significant difference in frequencies or means exists among hospitals.

${ }^{b}$ Number of planned procedures $=$ number of individual planned procedures as documented in the record for the individual surgical case.

Cl, confidence interval; ENT, ear-nose-throat; HN, head-neck; Gyn, gynecology; GynOnc, gynecologic oncology;

UroGyn, urologic gynecology.

at the hospital nearly 20 minutes later than patients of other departments, patients of neurosurgery waited approximately 60 minutes past scheduled surgery time for placement in the OR and 101 minutes to start of surgical procedure(s). For those patients who arrived late, only $5 \%$ were listed as delayed secondary to patient fault; however, the majority of the time no documented reason was listed if the patient arrived late. If looking at only those whose reasons were documented, it accounted for $14 \%$ of documented delay. Physician fault was the highest, at $20 \%$ of all patient late arrivals, and accounted for $52 \%$ of documented delay. 
Table 2. Total Number and Percentage of Delays With Mean Delay Time for First Surgeries

\begin{tabular}{|c|c|c|c|}
\hline Hospital and department & Total $\mathbf{n}$ & $\begin{array}{c}\text { Delayed cases, } \\
\mathrm{n}(\%) \\
\end{array}$ & $\begin{array}{c}\text { Delay in minutes, } \\
\text { mean }(95 \% \mathrm{Cl})^{\mathrm{a}}\end{array}$ \\
\hline $\begin{array}{l}\text { All hospitals } \\
\text { General surgery } \\
\text { ENT, HN, Oral } \\
\text { Gyn, GynOnc, UroGyn } \\
\text { Urology } \\
\text { Orthopedics } \\
\text { Neurosurgery } \\
\text { Other }\end{array}$ & $\begin{array}{c}5,598 \\
1,490 \\
295 \\
1,301 \\
282 \\
1,490 \\
399 \\
341\end{array}$ & $\begin{array}{c}4,944(88.3) \\
1,387(93.1) \\
221(74.9) \\
1,109(85.2) \\
243(86.2) \\
1,296(87.0) \\
390(97.7) \\
298(87.4)\end{array}$ & $\begin{array}{l}28.2(27.3-29.0) \\
33.9(32.0-35.7) \\
26.9(23.7-30.2) \\
15.1(14.0-16.2) \\
32.1(28.3-35.9) \\
22.8(21.6-24.0) \\
62.9(58.7-67.2) \\
25.7(22.3-29.4)\end{array}$ \\
\hline $\begin{array}{l}\text { Hospital } 1 \\
\text { General surgery } \\
\text { ENT, HN, Oral } \\
\text { Gyn, GynOnc, UroGyn } \\
\text { Urology } \\
\text { Orthopedics } \\
\text { Neurosurgery } \\
\text { Other }\end{array}$ & $\begin{array}{c}1,848 \\
732 \\
94 \\
54 \\
96 \\
448 \\
348 \\
76\end{array}$ & $\begin{array}{l}1,797(97.2) \\
710(97.0) \\
93(98.9) \\
53(98.1) \\
93(96.9) \\
429(95.8) \\
343(98.6) \\
76(100)\end{array}$ & $\begin{array}{l}52.4(50.7-54.0) \\
49.9(47.5-52.2) \\
48.2(43.5-52.9) \\
63.4(50.9-76.2) \\
58.8(52.6-65.0) \\
40.5(38.0-43.1) \\
69.1(64.7-73.5) \\
56.3(46.5-66.0)\end{array}$ \\
\hline $\begin{array}{l}\text { Hospital } 2 \\
\text { General surgery } \\
\text { ENT, HN, Oral }{ }^{\mathrm{b}} \\
\text { Gyn, GynOnc, UroGyn } \\
\text { Urology } \\
\text { Orthopedics } \\
\text { Neurosurgery } \\
\text { Other }\end{array}$ & $\begin{array}{c}1,218 \\
299 \\
1 \\
275 \\
56 \\
511 \\
0 \\
76\end{array}$ & $\begin{array}{c}987(81.0) \\
258(86.3) \\
0(--) \\
214(77.8) \\
38(67.9) \\
416(81.4) \\
0(--) \\
61(80.3)\end{array}$ & $\begin{array}{c}15.1(13.5-16.7) \\
20.4(14.7-26.1) \\
--(--) \\
13.7(11.7-15.7) \\
15.9(11.0-20.9) \\
12.1(11.1-13.2) \\
--(--) \\
17.2(13.7-20.7)\end{array}$ \\
\hline $\begin{array}{l}\text { Hospital } 3 \\
\text { General surgery } \\
\text { ENT, HN, Oral } \\
\text { Gyn, GynOnc, UroGyn } \\
\text { Urology } \\
\text { Orthopedics } \\
\text { Neurosurgery } \\
\text { Other }\end{array}$ & $\begin{array}{c}2,532 \\
459 \\
200 \\
972 \\
130 \\
531 \\
51 \\
189\end{array}$ & $\begin{array}{c}2,160(85.3) \\
419(91.3) \\
128(64.0) \\
842(86.6) \\
112(86.2) \\
451(84.9) \\
47(92.2) \\
161(85.2)\end{array}$ & $\begin{array}{l}14.0(13.5-14.5) \\
15.1(13.9-16.3) \\
11.5(9.91-13.1) \\
12.4(11.6-13.1) \\
15.5(13.1-17.8) \\
15.7(14.5-17.0) \\
17.8(13.3-22.2) \\
14.8(12.3-17.3)\end{array}$ \\
\hline
\end{tabular}

${ }^{a}$ Equivalent to mean deviation from scheduled surgery to patient in-room time for delayed cases.

${ }^{b}$ The single surgical patient was placed in the operating room 3 minutes prior to scheduled surgery time.

Cl, confidence interval; ENT, ear-nose-throat; HN, head-neck; Gyn, gynecology; GynOnc, gynecologic oncology;

UroGyn, urologic gynecology.

Mean event times by hospital facility and service department combination revealed that patient arrival times were consistently $<2$ hours prior to scheduled surgery time (Figure 1). For Hospital 2 and Hospital 3 only, in-room times were approximately 10-15 minutes later than scheduled. However, for all departments at Hospital 1, patient arrival, in-room placement and procedure start times were noticeably later, suggesting a significant influence of delayed times from Hospital 1 on department and overall averages.

Documentation of delay and surgical time in the records was noted to be suboptimal. Procedure start was not documented for 21 cases, and anesthesia start was not documented for 82 cases. Nearly $60 \%$ of delayed cases had no documented reasons for delay (Figure 2). Physicians were faulted for $52 \%$ of documented late starts; the remainder were attributed to anesthesia $(15 \%)$, the patient $(13 \%)$, staff $(9 \%)$, other sources $(6 \%)$ and the facility (5\%). Reasons for delay differed somewhat among hospital facilities, with a higher rate of documented reasons for delay (only 39\% of unknown fault) and higher rates of anesthesia (21\%) and staff $(15 \%)$ faults for documented cases at Hospital 2 than other hospitals. Cases at Hospital 3 revealed significantly less documentation $(67 \%$ of unknown 
Table 3. Mean Deviations From Scheduled Surgery Time to Patient Arrival at Hospital, Placement of Patient in the Operating Room, Start of Anesthesia, and Start of Procedure; and Mean Lengths of Intervals Between Events

\begin{tabular}{|c|c|c|c|c|c|c|}
\hline Event & $\begin{array}{l}\text { Hospital } \\
\text { facility }\end{array}$ & $\mathbf{n}$ & $\begin{array}{c}\text { Minutes, } \\
\text { mean }(95 \% \mathrm{Cl})^{\mathrm{a}} \\
\end{array}$ & $\begin{array}{c}\text { Service } \\
\text { department }\end{array}$ & $\mathbf{n}$ & $\begin{array}{c}\text { Minutes, } \\
\text { mean }(95 \% \mathrm{CI})^{\mathrm{a}}\end{array}$ \\
\hline \multicolumn{7}{|c|}{ Time relative to scheduled surgery time: } \\
\hline $\begin{array}{l}\text { Patient arrival } \\
\text { at hospital }\end{array}$ & $\begin{array}{l}\text { All hospitals } \\
\text { Hospital } 1 \\
\text { Hospital } 2 \\
\text { Hospital } 3\end{array}$ & $\begin{array}{l}4,871 \\
1,433 \\
1,071 \\
2,367\end{array}$ & $\begin{array}{c}-104.6(-105.4 \text { to }-103.8) \\
-95.4(-97.2 \text { to }-93.6) \\
-108.3(-110.2 \text { to }-106.4) \\
-108.5(-109.2 \text { to }-107.7)\end{array}$ & $\begin{array}{c}\text { General surgery } \\
\text { ENT, HN, Oral } \\
\text { Gyn } \\
\text { Urology } \\
\text { Orthopedics } \\
\text { Neurosurgery } \\
\text { Other }\end{array}$ & $\begin{array}{c}1,170 \\
279 \\
1,221 \\
236 \\
1,347 \\
317 \\
301\end{array}$ & $\begin{array}{l}-105.0(-107.0 \text { to }-102.9) \\
-103.1(-105.7 \text { to }-100.5) \\
-109.0(-110.2 \text { to }-107.8) \\
-103.7(-107.3 \text { to }-100.2) \\
-103.7(-105.0 \text { to }-102.5) \\
-88.1(-92.4 \text { to }-83.8) \\
-108.0(-111.2 \text { to }-104.8)\end{array}$ \\
\hline $\begin{array}{l}\text { Patient in } \\
\text { room }\end{array}$ & $\begin{array}{l}\text { All hospitals } \\
\text { Hospital } 1 \\
\text { Hospital } 2 \\
\text { Hospital } 3\end{array}$ & $\begin{array}{l}5,598 \\
1,848 \\
1,218 \\
2,532\end{array}$ & $\begin{array}{l}24.3(23.4 \text { to } 25.1) \\
50.6(49.0 \text { to } 52.2) \\
11.3(9.89 \text { to } 12.7) \\
11.3(10.7 \text { to } 11.8)\end{array}$ & $\begin{array}{c}\text { General surgery } \\
\text { ENT, HN, Oral } \\
\text { Gyn } \\
\text { Urology } \\
\text { Orthopedics } \\
\text { Neurosurgery } \\
\text { Other }\end{array}$ & $\begin{array}{l}1,490 \\
295 \\
1,301 \\
282 \\
1,490 \\
399 \\
341\end{array}$ & $\begin{array}{l}30.9(29.1 \text { to } 32.7) \\
19.0(16.1 \text { to } 21.9) \\
12.2(11.1 \text { to } 13.2) \\
26.6(23.0 \text { to } 30.3) \\
19.3(18.1 \text { to } 20.5) \\
61.4(57.1 \text { to } 65.7) \\
22.0(18.8 \text { to } 25.3)\end{array}$ \\
\hline $\begin{array}{l}\text { Anesthesia } \\
\text { start }\end{array}$ & $\begin{array}{l}\text { All hospitals } \\
\text { Hospital } 1 \\
\text { Hospital } 2 \\
\text { Hospital } 3\end{array}$ & $\begin{array}{l}5,525 \\
1,831 \\
1,203 \\
2,491\end{array}$ & $\begin{array}{l}24.8(23.9 \text { to } 25.6) \\
52.0(50.4 \text { to } 53.7) \\
11.7(10.2 \text { to } 13.2) \\
11.0(10.5 \text { to } 11.6)\end{array}$ & $\begin{array}{c}\text { General surgery } \\
\text { ENT, HN, Oral } \\
\text { Gyn } \\
\text { Urology } \\
\text { Orthopedics } \\
\text { Neurosurgery } \\
\text { Other }\end{array}$ & $\begin{array}{l}1,460 \\
295 \\
1,301 \\
265 \\
1,481 \\
397 \\
326\end{array}$ & $\begin{array}{l}31.9(29.9 \text { to } 33.69) \\
19.3(16.3 \text { to } 22.3) \\
12.1(11.0 \text { to } 13.2) \\
28.5(24.6 \text { to } 32.4) \\
19.7(18.6 \text { to } 20.9) \\
62.1(57.9 \text { to } 66.3) \\
23.2(19.7 \text { to } 26.6)\end{array}$ \\
\hline $\begin{array}{l}\text { Procedure } \\
\text { start }\end{array}$ & $\begin{array}{l}\text { All hospitals } \\
\text { Hospital } 1 \\
\text { Hospital } 2 \\
\text { Hospital } 3\end{array}$ & $\begin{array}{l}5,586 \\
1,844 \\
1,214 \\
2,528\end{array}$ & $\begin{array}{l}51.9(50.9 \text { to } 52.8) \\
83.7(81.8 \text { to } 85.7) \\
39.6(38.1 \text { to } 41.2) \\
34.5(33.8 \text { to } 35.1)\end{array}$ & $\begin{array}{c}\text { General surgery } \\
\text { ENT, HN, Oral } \\
\text { Gyn } \\
\text { Urology } \\
\text { Orthopedics } \\
\text { Neurosurgery } \\
\text { Other }\end{array}$ & $\begin{array}{c}1,489 \\
294 \\
1,298 \\
282 \\
1,487 \\
397 \\
339\end{array}$ & $\begin{array}{c}59.6(57.5 \text { to } 61.7) \\
38.3(35.0 \text { to } 41.5) \\
35.0(33.8 \text { to } 36.2) \\
53.4(48.6 \text { to } 58.2) \\
48.7(47.5 \text { to } 50.0) \\
101.8(97.1 \text { to } 106.6) \\
47.8(43.7 \text { to } 51.9)\end{array}$ \\
\hline $\begin{array}{l}\text { Arrival-to- } \\
\text { room }\end{array}$ & $\begin{array}{l}\text { All hospitals } \\
\text { Hospital } 1 \\
\text { Hospital } 2 \\
\text { Hospital } 3\end{array}$ & $\begin{array}{l}4,871 \\
1,433 \\
1,071 \\
2,367\end{array}$ & $\begin{array}{l}127.4(126.4 \text { to } 128.4) \\
145.8(143.3 \text { to } 148.4) \\
119.7(118.0 \text { to } 121.5) \\
119.7(118.7 \text { to } 120.6)\end{array}$ & $\begin{array}{c}\text { General surgery } \\
\text { ENT, HN, Oral } \\
\text { Gyn } \\
\text { Urology } \\
\text { Orthopedics } \\
\text { Neurosurgery } \\
\text { Other }\end{array}$ & $\begin{array}{c}1,170 \\
279 \\
1,221 \\
236 \\
1,347 \\
317 \\
301\end{array}$ & $\begin{array}{l}134.6(132.4 \text { to } 136.9) \\
120.8(116.9 \text { to } 124.8) \\
121.0(119.5 \text { to } 122.6) \\
132.9(128.2 \text { to } 137.5) \\
122.0(120.4 \text { to } 123.6) \\
148.1(142.1 \text { to } 154.2) \\
128.8(124.1 \text { to } 133.4)\end{array}$ \\
\hline $\begin{array}{l}\text { Room-to- } \\
\text { anesthesia }\end{array}$ & $\begin{array}{l}\text { All hospitals } \\
\text { Hospital } 1 \\
\text { Hospital } 2 \\
\text { Hospital } 3\end{array}$ & $\begin{array}{l}5,525 \\
1,831 \\
1,203 \\
2,491\end{array}$ & $\begin{array}{c}0.44(0.32 \text { to } 0.56) \\
1.52(1.29 \text { to } 1.75) \\
0.31(-0.03 \text { to } 0.64) \\
-0.29(-0.40 \text { to }-0.17)\end{array}$ & $\begin{array}{c}\text { General surgery } \\
\text { ENT, HN, Oral } \\
\text { Gyn } \\
\text { Urology } \\
\text { Orthopedics } \\
\text { Neurosurgery } \\
\text { Other }\end{array}$ & $\begin{array}{l}1,460 \\
295 \\
1,301 \\
265 \\
1,481 \\
397 \\
326\end{array}$ & $\begin{array}{c}0.69(0.47 \text { to } 0.91) \\
0.24(-0.07 \text { to } 0.54) \\
-0.09(-0.41 \text { to } 0.24) \\
0.91(0.35 \text { to } 1.46) \\
0.34(0.16 \text { to } 0.52) \\
1.42(0.92 \text { to } 1.91) \\
0.51(0.14 \text { to } 0.88)\end{array}$ \\
\hline $\begin{array}{l}\text { Anesthesia- } \\
\text { to-procedure }\end{array}$ & $\begin{array}{l}\text { All hospitals } \\
\text { Hospital } 1 \\
\text { Hospital } 2 \\
\text { Hospital } 3\end{array}$ & $\begin{array}{l}5,515 \\
1,828 \\
1,199 \\
2,488\end{array}$ & $\begin{array}{l}27.3(27.0 \text { to } 27.6) \\
31.9(31.1 \text { to } 32.6) \\
28.1(27.5 \text { to } 28.8) \\
23.6(23.2 \text { to } 23.9)\end{array}$ & $\begin{array}{c}\text { General surgery } \\
\text { ENT, HN, Oral } \\
\text { Gyn } \\
\text { Urology } \\
\text { Orthopedics } \\
\text { Neurosurgery } \\
\text { Other }\end{array}$ & $\begin{array}{l}1,460 \\
294 \\
1,298 \\
265 \\
1,478 \\
396 \\
324\end{array}$ & $\begin{array}{l}28.1 \text { (27.4 to } 28.8) \\
19.1(18.2 \text { to } 19.9) \\
22.9(22.4 \text { to } 23.5) \\
26.8(25.0 \text { to } 28.7) \\
29.2(28.7 \text { to } 29.7) \\
39.6(37.8 \text { to } 41.4) \\
25.3 \text { (23.9 to } 26.8)\end{array}$ \\
\hline
\end{tabular}

${ }^{a}$ Computed as event time minus time of scheduled surgery, where negative values indicate that events occurred before scheduled surgery time. For periods between events, computed as time of Event 2 minus time of Event 1, where negative values indicate that Event 2 occurred before Event 1.

${ }^{b}$ Gynecology, gynecologic oncology, and urologic gynecology are collectively referred to as Gyn.

$\mathrm{Cl}$, confidence interval; ENT, ear-nose-throat; HN, head-neck. 


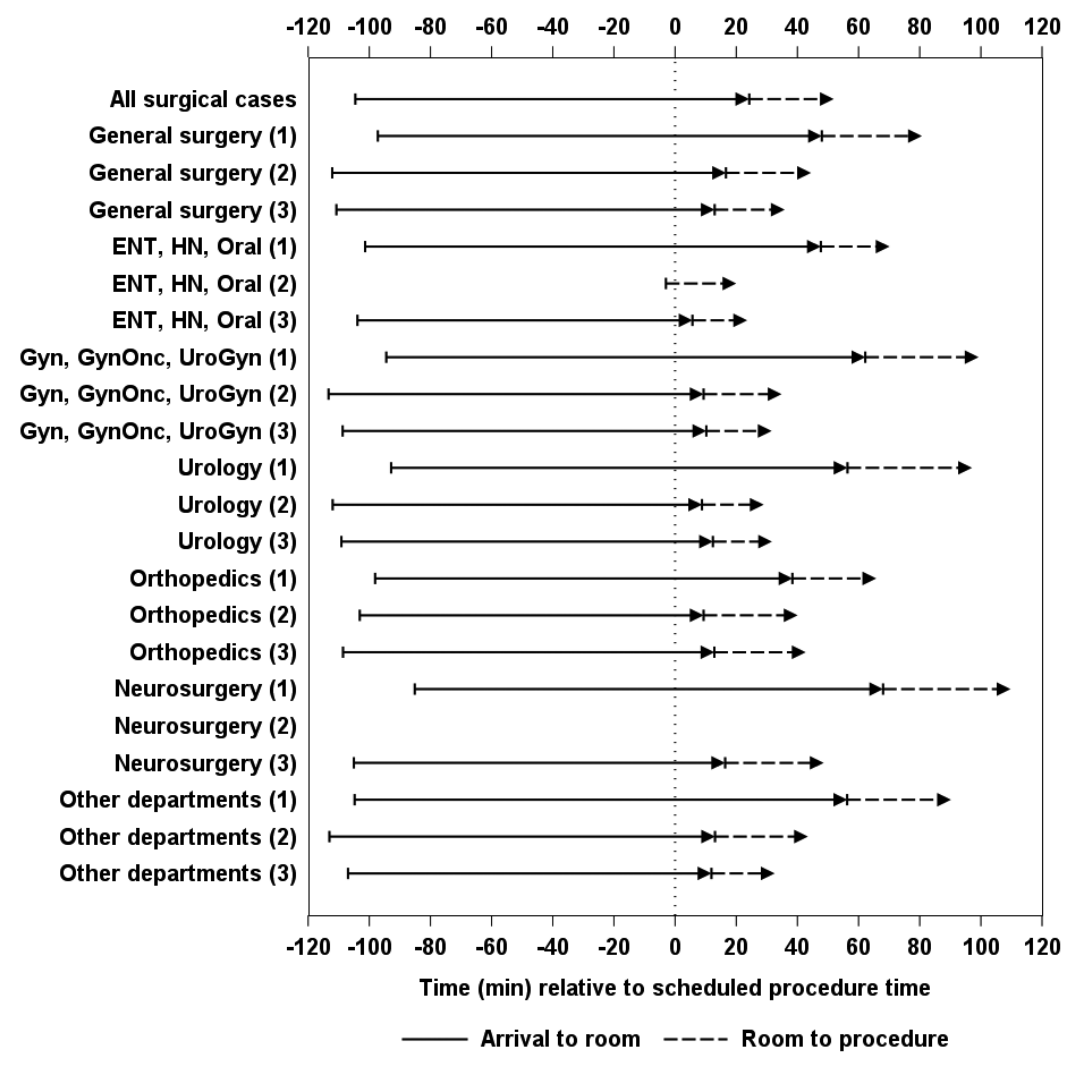

Figure 1. Periods between mean times of patient arrival at the hospital, placement in the operating room, and procedure start for first-of-the-day surgeries performed in various departments at three urban hospitals (designated 1, 2 and 3). Patients with overnight stays prior to surgery were not included in calculations of mean arrival time, marking the start of the arrival-toroom period. ENT, ear-nose-throat; $H N$, head-neck; Gyn, gynecology; GynOnc, gynecologic oncology; UroGyn, urologic gynecology. fault) and greater physician fault (56\%) than other hospitals. Delay documentation and fault patterns at Hospital 1 mirrored overall outcomes across hospitals. Gynecology, gyn-oncology and uro-gynecology collectively revealed higher physician fault, while urology demonstrated greater fault of facility. Lastly, orthopedics showed higher rates of anesthesia and staff faults than other departments.

Single- and multivariable mixed models, in combination, established patient age, late patient arrival to the hospital, service department and hospital facility as significant predictors of first-case delay (Table 4). Without statistical significance, all interactions were removed from both multivariable models. Based on the better fitting multivariable model, odds of delay increased $9 \%$ for each 10-year increase in patient age and were $35 \%$ greater for late-arriving patients than those who arrived $\geq 2$ hours in advance. Relative to general surgery, the odds of delay were significantly $(35-77 \%)$ less for surgeries in all other service departments, except neurosurgery. The odds of surgery delay also were significantly (80-85\%) less at Hospital 2 and Hospital 3 than Hospital 1.

\section{DISCUSSION}

Across three high-volume urban hospitals of the same large health care system, we found that over $88 \%$ of first-of-the-day nonemergency surgeries were delayed. In marked contrast, national benchmark data indicate that, in U.S. hospitals of the 50th percentile, $64 \%$ of firstcase surgeries start on time (while $91 \%$ of cases start on time in hospitals of the 95th percentile) ${ }^{8}$ On average, patients in our health care system waited 24 minutes beyond scheduled surgery time to be placed in the OR and nearly 1 hour for procedure start. Across hospitals, the most commonly documented reasons for delay were the physician, anesthesia and patient, but nearly $60 \%$ of delayed cases had no delay documentation.

Timeliness of patient arrival to the hospital determines the feasibility of timely preparation of the patient prior to surgery. In our system, $65 \%$ of patients arrived late, increasing their odds of a late surgical start by $35 \%$. Hospital 3 showed significantly more late arrivals $(67 \%)$ than the other two hospitals $(63 \%)$, but patients at Hospital 2 arrived later (95 minutes before scheduled surgery), on average, than patients at the other two hospitals (108 minutes). Adding to the difficulty of 

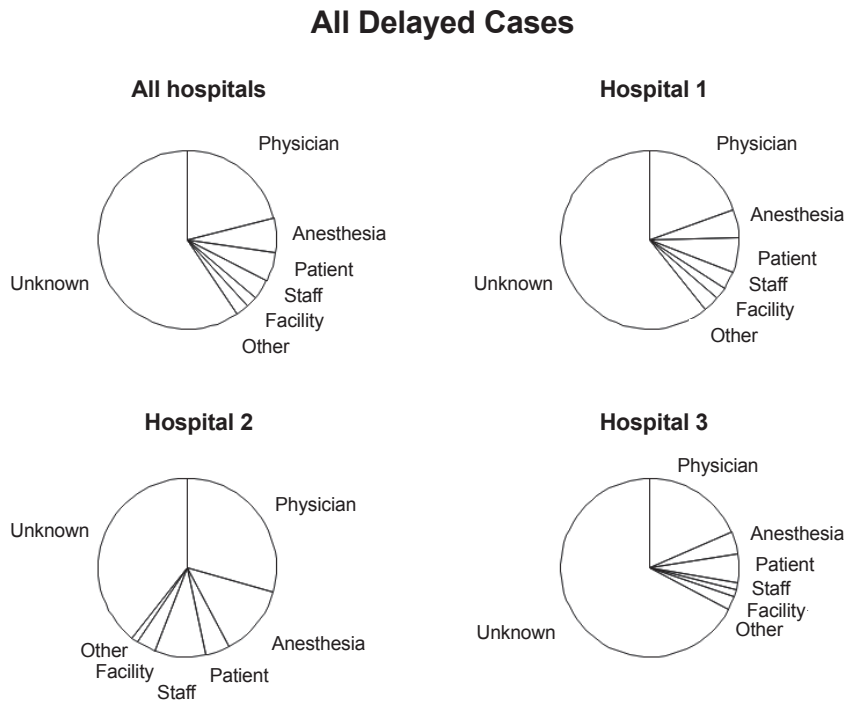

Cases with Documented Delay Reasons
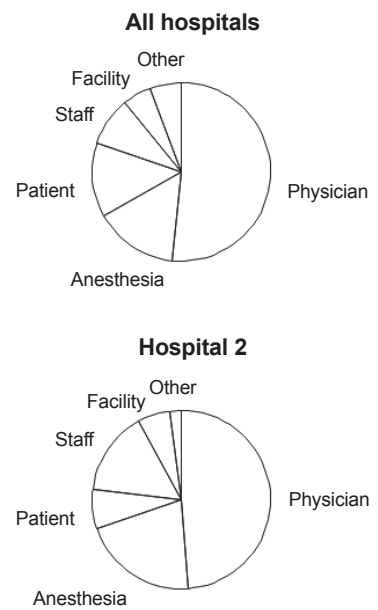

Figure 2. Reasons for delays in first-of-the-day surgeries at each of three hospitals. Note: Reasons are presented as the percentage fault in delay. Surgeries were considered delayed if patient in-room time occurred after the scheduled surgery time. Only surgical cases with delayed starts are included.

pinpointing failed steps in OR workflow, patients arrived late to the hospital in $65 \%$ of all cases and $75 \%$ of same-day arrivals but were faulted for only $13 \%$ of start delays. This discrepancy between late arrival and assigned fault of the patient may be secondary to nonstandardized methods of documentation, but other potential explanations exist. For example, staff may have felt that one or more other causes of delay were more influential or, on a personal level, had difficulty assigning blame to the patient. A solution to this problem could be to add a section in the delay cause area such as: "Patient late (yes/no); if yes, did it cause a delay in start time?"

Moreover, a patient's odds of experiencing late inroom placement increased with age. This could be secondary to increased patient complexity and would be interesting to include number of medical comorbidities in the future. Departments also exhibited variability, with patients of neurosurgery arriving latest ( 88 minutes before scheduled surgery) and those of gynecology, gynecologic oncology and urologic gynecology, collectively, arriving earliest (109 minutes). Although no national standard exists for patient arrival time prior to surgery, patients throughout our system are requested to arrive at least 2 hours early to ensure adequate time for completion or updating of documentation. This is an interesting point of reference in that most cases started 128 minutes after arrival in our system, making a 2-hour prior arrival almost inadequate. Early arrival also permits time for necessary laboratory testing as well as the planning and subsequent preparation of anesthesia.

Previous strategies for reducing OR cancellations and in-room delays include the use of anesthesiologistdirected preoperative clinic visits, which may also prove useful for limiting the cascading effects of late patient arrival on workflow efficiency. ${ }^{9}$ By performing preoperative consulting, testing and anesthesia risk assessment ahead of time during a separate 50-minute appointment, the success of anesthesiologists and other OR staff in terms of timeliness might be less contingent on patient adherence to recommended arrival time. Other possible interventions include systemwide, standardized preoperative packets for patients and checklists for medical staff. ${ }^{10}$ More investigation needs to be completed in relation to patient late arrival and cause. Future directions for investigation include the association between distance from patients' homes to the hospital and arrival time, the average amount of time nursing and staff need to prepare patients and if the number of patient comorbidities impacts preparation time the same day of surgery.

Physicians, including surgeons and anesthesiologists, were identified as significant causes of delay in both our health care system and systems evaluated 
Table 4. Odds Ratios, Representing Effect Sizes, for Fixed Effects in Single- and Multivariable Models of Delayed In-Room Time for First-of-the-Day Surgeries

\begin{tabular}{|c|c|c|}
\hline Fixed effect & $\begin{array}{c}\text { Single-variable models, } \\
\text { odds ratio }(95 \% \mathrm{CI})\end{array}$ & $\begin{array}{c}\text { Multivariable model, } \\
\text { odds ratio }(95 \% \mathrm{Cl})\end{array}$ \\
\hline Patient age ${ }^{a}$ & $1.104(1.047-1.163)^{b}$ & $1.089(1.028-1.154)^{b}$ \\
\hline $\begin{array}{l}\text { Patient sex } \\
\text { Male } \\
\text { Female }\end{array}$ & $\begin{array}{c}\text { Reference } \\
1.040(0.855-1.264)\end{array}$ & $\begin{array}{c}\text { Reference } \\
0.947(0.755-1.189)\end{array}$ \\
\hline $\begin{array}{l}\text { Patient race/ethnicity } \\
\text { White non-Hispanic } \\
\text { Black non-Hispanic } \\
\text { Hispanic/Latino(a) }\end{array}$ & $\begin{array}{c}\text { Reference } \\
0.945(0.743-1.202) \\
0.676(0.492-0.929)^{b}\end{array}$ & $\begin{array}{c}\text { Reference } \\
1.025(0.791-1.328) \\
0.821(0.582-1.158)\end{array}$ \\
\hline Patient body mass index ${ }^{c}$ & $1.075(0.963-1.200)$ & $1.058(0.943-1.187)$ \\
\hline $\begin{array}{l}\text { Patient arrival at hospital } \\
\text { On time ( } \geq 2 \text { hours before surgery) } \\
\text { Late ( }<2 \text { hours before surgery) }\end{array}$ & $\begin{array}{c}\text { Reference } \\
1.244(1.037-1.492)^{\mathrm{b}}\end{array}$ & $\begin{array}{c}\text { Reference } \\
1.346(1.108-1.636)^{\mathrm{b}}\end{array}$ \\
\hline Number of planned procedures ${ }^{d}$ & $1.106(0.989-1.236)$ & $1.097(0.974-1.236)$ \\
\hline Years of surgeon experience ${ }^{e}$ & $0.981(0.897-1.073)$ & $0.990(0.899-1.091)$ \\
\hline $\begin{array}{l}\text { Provider department } \\
\text { General surgery } \\
\text { ENT, HN, Oral } \\
\text { Gyn, GynOnc, UroGyn } \\
\text { Urology } \\
\text { Orthopedics } \\
\text { Neurosurgery }\end{array}$ & $\begin{array}{c}\text { Reference } \\
0.213(0.149-0.305)^{\mathrm{b}} \\
0.613(0.468-0.802)^{\mathrm{b}} \\
0.516(0.341-0.780)^{\mathrm{b}} \\
0.607(0.468-0.789)^{\mathrm{b}} \\
1.689(0.828-3.443)\end{array}$ & $\begin{array}{c}\text { Reference } \\
0.231(0.159-0.335)^{\mathrm{b}} \\
0.648(0.478-0.878)^{\mathrm{b}} \\
0.524(0.336-0.816)^{\mathrm{b}} \\
0.592(0.448-0.783)^{\mathrm{b}} \\
0.988(0.461-2.117)\end{array}$ \\
\hline $\begin{array}{l}\text { Hospital } \\
\text { Hospital } 1 \\
\text { Hospital } 2 \\
\text { Hospital } 3\end{array}$ & $\begin{array}{c}\text { Reference } \\
0.130(0.087-0.194)^{\mathrm{b}} \\
0.173(0.118-0.254)^{\mathrm{b}}\end{array}$ & $\begin{array}{c}\text { Reference } \\
0.147(0.094-0.230)^{\mathrm{b}} \\
0.209(0.137-0.319)^{\mathrm{b}}\end{array}$ \\
\hline
\end{tabular}

alncrease in odds of delayed in-room time per 10-year increase in age.

${ }^{b}$ Difference between odds ratio and 1.0 is statistically significant.

cIncrease in odds of delayed in-room time per $10 \mathrm{~kg} / \mathrm{m}^{2}$ increase in body mass index.

dIncrease in odds of delayed in-room time per 1 additional planned surgical procedure.

elncrease in odds of delayed in-room time per 10-year increase in surgeon experience.

Cl, confidence interval; ENT, ear-nose-throat; HN, head-neck; Gyn, gynecology; GynOnc, gynecologic oncology;

UroGyn, urologic gynecology.

in published studies. ${ }^{6,11,12}$ Strategies for reducing surgeon-caused delays may include education, peer review and punitive actions. Preoperative briefings, beginning prior to the start of the day, have demonstrated significant value for reducing delays as well as improvements in patient safety. ${ }^{13,14}$ Simple education of the surgeon, monitoring of surgeon arrival times and sending out email reminders to arrive 20 minutes prior to case start resulted in dramatic improvement at one institution, where the percentage of on-time starts increased from $24 \%$ to $80 \% .^{12}$ Documentation of reason for physician delay also would be helpful for feedback and process improvement, as would having subcategories of what was not completed by the physician, such as consent, history and physician or late arrival. During the study period, the system was not documenting the cause of physician delay. 
As anesthesia was the second most commonly documented cause of delayed starts in our system, initiating the use of anesthesiologist-directed preoperative clinic visits or a separate preanesthesia testing area also might prove beneficial for reducing anesthesia's contribution to start delays.

In this study, not only did regression analysis reveal differential odds of case delay among facilities and departments, but delay documentation suggested variability in sources of delay. Anesthesia and staff were most faulted for delays at Hospital 2, whereas physician fault and no documentation of fault were most prevalent at Hospital 3. Other than late patient arrival, no salient causes of case delay were observed at Hospital 1. However, odds of delay were five times greater at Hospital 1 than the other two, suggesting that important influences associated with the facility went undescribed. Similarly, the departments of neurosurgery and general surgery showed higher frequencies of delay, longer delay periods and two times greater odds of delay than other departments, but no discriminating sources of delay stood out. Among other departments, physicians were most faulted for delays in gynecologic surgeries, urology recorded greater fault of the facility than other departments and orthopedics showed higher rates of anesthesia and staff faults. Given such inconsistency in delay sources, efforts to increase on-time starts may be most effective when departments or facilities representing problem areas are strategically targeted and interventions are tailored to overcome the most recognized challenges.

We discovered that $60 \%$ of delayed cases in our system were incompletely described in the electronic medical record in terms of delay cause or attributable fault. Observed deficiencies in documentation were certainly surprising because hospitals in our system uniformly use on-time start as a quality benchmark. However, lacking documentation may be secondary to inconsistent reporting of delays. As individual hospitals (and, perhaps, ORs) have different protocols in place for determining how and by whom documentation occurs, variability in completeness of documentation among facilities (from $33 \%$ at Hospital 3 to $61 \%$ at Hospital 2) and departments (from 30\% in ENT/ head-neck/oral surgery to $51 \%$ in orthopedics) is then less surprising. Implementation of standardized methodology for reporting delays is a logical strategy to overcome inconsistencies among ORs and improve the comprehensiveness and quality of documentation. Also, determining the types of delay to be recorded and ensuring a higher specificity of the cause of delay would be beneficial. However, prior to implementation, systemwide training that focuses on the use of new methods within the current electronic health record framework would be required. By improving data quality and more accurately tracking causes of case delay, problem areas could be more readily identified, leading to reduction in OR case delays. ${ }^{5}$

Ultimately, decreased frequency and length of delay in first-of-the-day surgeries may prove beneficial for patient satisfaction, patient safety and resource efficiency. For the three hospital facilities in our study, a total loss of 2,320 hours and 46 minutes had accrued over the course of the study period (1.5 years) due to late OR starts. Based on published figures ${ }^{15,16}$ and adjusting for inflation, we estimated the cost of delay to be $\$ 519,388$ in total lost revenue. However, this amount may be considered a conservative estimate of dollars lost because the financial costs of the surgeon and anesthesia are not incorporated.

A major strength of this study is the inclusion of three large urban hospitals from the same regional health care system, which allowed for comparison among different patient populations and potentially increased the generalizability of our findings. Consequently, our study represents the first published comparison of OR workflow patterns among hospitals in a single U.S. health care system. Limitations of our study are associated with its retrospective nature. For example, due to retrospective collection and review of electronic medical record data, we were unable to gather complete information on causes of delay. Only a prospective approach to workflow evaluation entailing universal preparatory training of medical staff in the OR system would have allowed for increased consistency and completeness in documentation. However, as the overarching goal of our effort was to identify problem areas within OR workflow, an initial evaluation of data content and quality was a required first step.

We also did not incorporate some variables in our analysis that may have influenced workflow in the OR setting. Such variables include patient-specific factors (e.g. regularity of visiting the facility, distance between home and facility, 
occupation and patient health status), surgeon-specific factors (e.g. surgical volumes, clinical workload, distance between home and facility), and employee perspectives regarding OR team communications, expectations and resource inefficiencies. Documentation, tracking and reporting of patient-, surgeon- and staff-specific factors for delayed OR start times could help the development and implementation of targeted interventions and programs to improve OR efficiency.

\section{CONCLUSIONS}

In conclusion, we found significant delays in firstof-the-day surgical cases, in terms of both frequency and duration, at all three facilities. At minimum, the reduction of delays will require increased patient adherence to recommended arrival times, more complete documentation of delays by medical staff and greater consistency in methods of documentation and workflow patterns among facilities and departments. Next steps could include establishment of a Plan-Do-Study-Act cycle, ${ }^{17}$ wherein any or several of the aforementioned interventions are designed, implemented, evaluated and incorporated into standard protocol. Ideally, execution of the system's Plan-Do-Study-Act cycle would first occur at one or few centers and then be rolled out to other centers following demonstrable success. To ensure success, multidisciplinary teams and strategies should guide the process, and continuous education of staff in all OR settings should be viewed as a necessary tool. Lastly, insight gained from further study of patient, surgeon, workplace and other factors influencing OR workflow may prove useful during all phases of the cycle.

\section{Patient-Friendly Recap}

- The first surgery of the day in any operating room sets the pace for subsequently scheduled procedures.

- The authors found that most first surgeries do not start on time, likely resulting in higher overall health care costs.

- Causes of these frequent delays ranged from patients not arriving at the hospital within the recommended timeframe to late physicians to anesthesia-related issues, among others.

- Often, the reason for delay was not documented in the medical record, creating a substantial obstacle for future development of potential solutions.

\section{Conflicts of Interest}

None.

\section{Disclaimer for Member of Armed Forces}

Dr. Cox Bauer is a captain in the United States Air

Force. This research was completed on inactive duty.

\section{References}

1. Harders M, Malangoni MA, Weight S, Sidhu T. Improving operating room efficiency through process redesign. Surgery. 2006;140:509-14; discussion 514-6. CrossRef

2. Schuster M, Pezzella M, Taube C, Bialas E, Diemer M, Bauer M. Delays in starting morning operating lists: an analysis of more than 20,000 cases in 22 German hospitals. Dtsch Arztebl Int. 2013;110:237-43.

3. Saha P, Pinjani A, Al-Shabibi N, Madari S, Ruston J, Magos A. Why we are wasting time in the operating theatre? Int $J$ Health Plann Manage. 2009;24:225-32. CrossRef

4. Bhatt AS, Carlson GW, Deckers PJ. Improving operating room turnover time: a systems based approach. J Med Syst. 2014;38:148. CrossRef

5. Foglia RP, Alder AC, Ruiz G. Improving perioperative performance: the use of operations management and the electronic health record. JPediatr Surg. 2013;48:95-8. CrossRef

6. Overdyk FJ, Harvey SC, Fishman RL, Shippey F. Successful strategies for improving operating room efficiency at academic institutions. Anesth Analg. 1998;86:896-906. CrossRef

7. Seim AR, Sandberg WS. Shaping the operating room and perioperative systems of the future: innovating for improved competitiveness. Curr Opin Anesthesiol. 2010;23:765-71. CrossRef

8. Foster T. Data for benchmarking your OR's performance. $O R$ Manager. 2012;28:13-6.

9. Ferschl MB, Tung A, Sweitzer B, Huo D, Glick DB. Preoperative clinic visits reduce operating room cancellations and delays. Anesthesiology. 2005;103:855-9. CrossRef

10. Panni MK, Shah SJ, Chavarro C, Rawl M, Wojnarwsky PK, Panni JK. Improving operating room first start efficiency value of both checklist and a pre-operative facilitator. Acta Anaesthesiol Scand. 2013;57:1118-23. CrossRef

11. Reynolds GW. Innovative solutions: does preadmission testing prevent delays for first-case starts? Dimens Crit Care Nurs. 2011;30:256-62. CrossRef

12. Fezza M, Palermo GB. Simple solutions for reducing firstprocedure delays. AORN J. 2011;93:450-4. CrossRef

13. Nundy S, Mukherjee A, Sexton JB, et al. Impact of preoperative briefings on operating room delays: a preliminary report. Arch Surg. 2008;143:1068-72. CrossRef

14. Jain AL, Jones KC, Simon J, Patterson MD. The impact of a daily pre-operative surgical huddle on interruptions, delays, and surgeon satisfaction in an orthopedic operating room: a prospective study. Patient Saf Surg. 2015;9:8. CrossRef

15. Dexter F, Epstein RH. Typical savings from each minute reduction in tardy first case of the day starts. Anesth Analg. 2009;108:1262-7. CrossRef

16. Bureau of Labor Statistics. CPI inflation calculator. http://www. bls.gov/data/inflation_calculator.htm. Accessed Aug. 17, 2015.

17. Taylor MJ, McNicholas C, Nicolay C, Darzi A, Bell D, Reed JE. Systematic review of the application of the plan-do-study-act method to improve quality in healthcare. BMJ Qual Saf. 2014;23:290-8. CrossRef

(C) 2016 Aurora Health Care, Inc. 